\title{
E-cigarettes more popular than tobacco among youth
}

$\mathrm{M}$

ore Canadian youth are choosing electronic cigarettes over their traditional tobacco counterpart, according to recently released government statistics. Among youth aged $15-19,20 \%$ have tried vaping, compared to $11 \%$ who smoke tobacco, states the Canadian Tobacco, Alcohol and Drugs Survey.

The vaping rate also hovers around $20 \%$ among young adults aged $20-24$, which falls closer to the $18 \%$ smoking rate for that age group. Both of these vaping rates for young people exceed the national average. Only $9 \%$ of Canadians aged 15 and up have ever tried an e-cigarette.

"We've never had a snapshot like this," said Margaret Bernhardt-Lowdon, executive director of the Manitoba Lung Association.

She called the rates of youth experimentation with e-cigarettes "concerning," and would like to see a ban for minors. E-cigarettes are not regulated like tobacco products, and therefore don't have restrictions related to age, use in public spaces or advertising.

Due to the lack of restrictions, there has been a drastic shift in the distribution and availability of e-cigarettes over the past five years. Specialty "vape shops" selling only e-cigarette products have been cropping up nationwide.

In the last two years in particular, the growth has been exponential, says Kate Ackerman, a founding director of

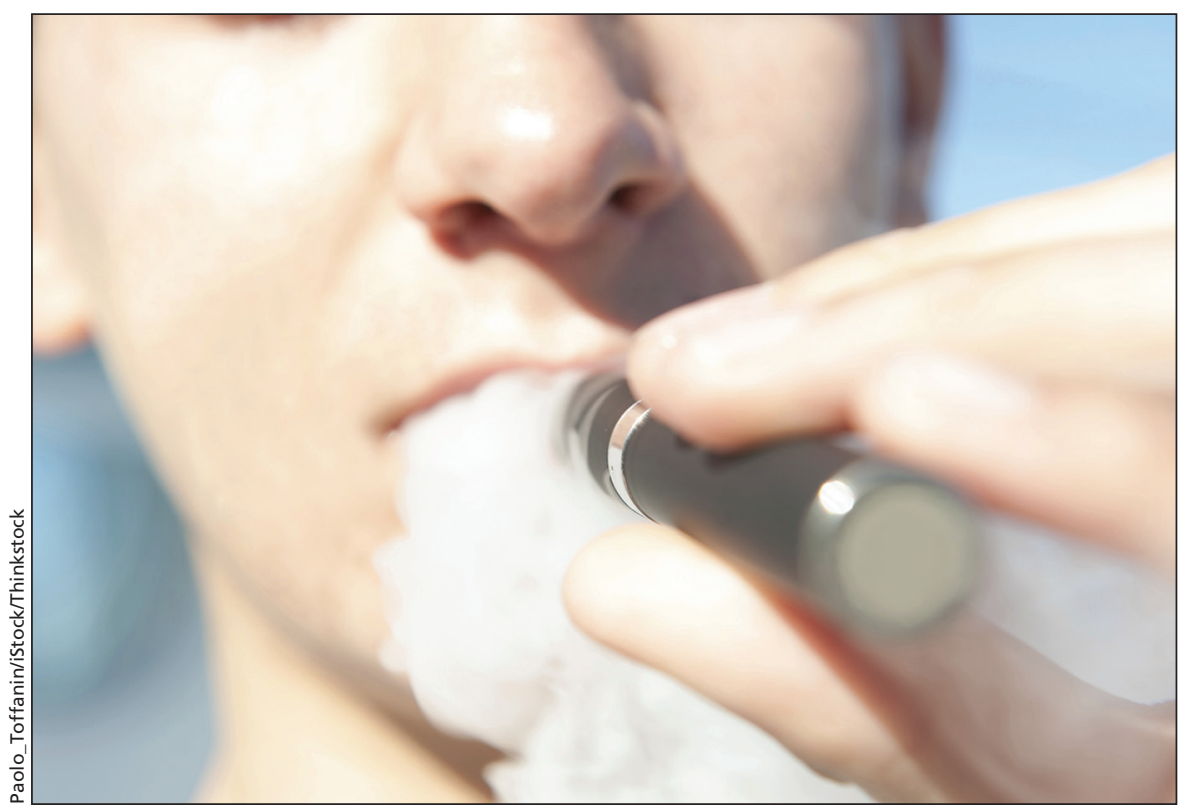

The high rate of experimentation with e-cigarettes among youth concerns health experts.

the Electronic Cigarette Trade Association of Canada.

E-cigarettes are legal in Canada, as long as they don't contain nicotine. Because nicotine is classified as a drug by Health Canada, it is regulated under the Food and Drugs Act. The federal government has banned the sale of nicotine e-liquid for electronic cigarettes for both adults and minors, but the products are still widely accessible despite the prohibition. About a quarter of users reported that the last ecigarette they used contained nicotine.

"We've been telling Health Canada for years now that e-cigarettes with nic- otine are readily available in the Canadian market despite the fact that they are illegal," says Melodie Tilson, policy director for the Non-Smokers' Rights Association. Retailers became bolder in their marketing and sales when it became clear that Health Canada was not enforcing their regulations, she says.

Health Canada has been issuing cease-and-desist orders to vape shops for several years, but according to Tilson, there has been no follow-up. "When complaints are registered, there is no action." - Amy Thatcher, CMAJ

CMAJ 2015. DOI:10.1503/cmaj.109-5010 